\title{
A comparison of sufentanil and fentanyl for patient- controlled epidural analgesia in arthroplasty
}

\author{
Hye Rim Jeon, Won Seok Chae, Se Jin Lee, Joon Ho Lee, Sung Hwan Cho, Sang Hyun Kim, Hee \\ Cheol Jin, Jeong Seok Lee, and Yong Ik Kim \\ Department of Anesthesiology and Pain Medicine, Soonchunhyang University Hospital, Bucheon, Korea
}

Background: The use of lipid soluble opioids such as fentanyl, alfentanil and sufentanil are recently on the increase for patient-controlled epidural analgesia (PCEA). In this study, the effects and adequate dose of sufentanil in arthroplasty were investigated.

Methods: Eighty patients scheduled for arthroplasty were enrolled for the study. Seventy-one patients (ASA physical status I-III) were randomly allocated into four groups. All groups received $0.1 \%$ ropivacaine through PCEA and each group received either fentanyl (group F: fentanyl $4 \mu \mathrm{g} / \mathrm{ml}$ ) or sufentanil (group S1: sufentanil $0.5 \mu \mathrm{g} / \mathrm{ml}$, group S2: sufentanil $0.75 \mu \mathrm{g} / \mathrm{ml}$, and group S3: sufentanil $1.0 \mu \mathrm{g} / \mathrm{ml}$ ). Postoperative pain scores were evaluated using VAS (visual analog scale, $0-10$ ) and side effects such as hypotension, nausea/vomiting, pruritus and the degree of satisfaction were evaluated at 1, 6, 12, 24, 48 hours after surgery.

Results: Postoperative pain score (VAS) decreased gradually and the highest VAS score was recorded at 1 hour postoperative for all four groups. There were no differences in the degree of satisfaction and postoperative pain score between all groups. The incidence of pruritus was significantly lower in group S1 than in groups S2 and S3.

Conclusions: The incidence of side effects were significantly lower in group S1 ( $0.1 \%$ ropivacaine plus sufentanil 0.5 $\mu \mathrm{g} / \mathrm{ml}$ ). Therefore, $0.5 \mu \mathrm{g} / \mathrm{ml}$ of sufentanil through PCEA is the recommended dose for postoperative pain control in arthroplasty. (Korean J Anesthesiol 2011; 60: 41-46)

Key Words: Epidural analgesia, Fentanyl, Ropivacaine, Sufentanil.

Received: May 18, 2010. Revised: 1st, June 21, 2010; 2nd, August 6, 2010. Accepted: August 12, 2010.

Corresponding author: Won Seok Chae, M.D., Department of Anesthesiology and Pain Medicine, Soonchunhyang University College of Medicine, 1174, Jung-1 dong, Wonmi-gu, Bucheon 420-767, Korea. Tel: 82-32-621-5327, Fax: 82-32-621-5322, E-mail: ch1s@schbc.ac.kr This is a theisis for a master's degree.

(c) This is an open-access article distributed under the terms of the Creative Commons Attribution Non-Commercial License (http:// creativecommons.org/licenses/by-nc/3.0/), which permits unrestricted non-commercial use, distribution, and reproduction in any medium, provided the original work is properly cited. 


\section{Introduction}

Hip or knee replacement arthroplasty are common in many elderly patients, and these surgeries are considerably more painful than other orthopedic surgeries. The pain can cause immense suffering to the patient, and also alter physiological functions induced by hormonal changes due to sympathetic nervous system activation. Cardiac function and vessel elasticity are decreased in the elderly, so the increase of sympathetic nervous system activity can stress the heart due to high blood pressure and/or rapid heart rate. This can increase the risk of myocardiac ischemia or infarction because the myocardiac oxygen demand exceeds its supply [1]. For this reason, early postoperative pain control should improve the outcome of surgery.

Patient-controlled epidural analgesia (PCEA) provides better results than intravenous pain control in orthopedic lower limb surgery [1]. Local anesthetics combined with opioids have been used in PCEA since opioids reduce the minimum local analgesic concentration (MLAC) of local anesthetics [2] and this dose-dependent effect of opioids can prevent local anestheticinduced postural hypotension and enable early ambulation $[1,3]$. Since lipophilic sufentanil appears to have a greater antinociceptive effect than hydrophilic morphine, a small dose of sufentanil is effective for pain control [4]. In addition, side effects such as pruritus and sedation are low [5] and sufentanil blocks $\mu$-receptor more selectively than fentanyl [1]. For the reason, it has been suggested that sufentanil has increased analgesic effects and fewer side effects than fentanyl. However, no study has evaluated the comparative analgesic effects of these two drugs in orthopedic lower limb surgery.

In this study, we performed a prospective, randomized study in patients undergoing arthroplasty to compare the effectiveness on pain and the incidence of side effects of the following two drugs: sufentanil-ropivacaine or fentanylropivacaine through PCEA. Secondly, we evaluated the optimal dose of epidural sufentanil.

\section{Materials and Methods}

The prospective study was performed after approval by the committee on Human Research. Eighty patients which were classified by the American society of anesthesiologists as status (ASA) I-III were scheduled for total knee replacement arthroplasty (TKRA), total hip replacement arthroplasty (THRA) and bipolar hemiarthroplasty. Exclusion criteria included a history of drug allergy and psychiatric disease, an 80 year patient age limit and contraindications to epidural anesthesia (preoperative coagulopathy and localized infection). All operations were performed by a single orthopedic surgeon.

As previous studies calculated the sample size based on $20 \%$ to $33 \%$ decrease in pain score [6-9], we calculated that a mean difference in VAS between groups of $30 \%$, with reduced pain scores in the sufentanil group, would permit a type 1 error rate of one-tailed $\alpha=0.05$ and a type 2 error of $\beta=0.20$. This analysis indicated that a sample size of 17 patients per group was essential. Nine patients were not included in this study for the following reasons; injection of analgesics immediately after surgery on ward in 5 patients, spontaneous epidural catheter removal in 3 patients, and error of PCA pump in 1 patient.

After routine monitors were placed in the operating room, catheters were inserted at the L3-4 or L4-5 interspace. We identified the epidural space using the loss of resistance (LOR) method and inserted a catheter of $4-10 \mathrm{~cm}$ to the cephalad from the skin. All catheters were tested for intravascular or subarachnoid placement with $3 \mathrm{ml}$ of $2 \%$ lidocaine containing $1: 200,000$ epinephrine. All epidural catheter insertions were performed by an experienced anesthesiologist.

General anesthesia was induced after epidural catheter insertion with $1.5 \mathrm{mg} / \mathrm{kg}$ propofol and $0.5-1.0 \mu \mathrm{g} / \mathrm{kg}$ fentanyl. Tracheal intubation was facilitated by $0.6 \mathrm{mg} / \mathrm{kg}$ rocuronium. All patients underwent mechanical ventilation with an equal mixture of oxygen and nitrous oxide. Anesthesia was maintained with $100-200 \mu \mathrm{g} / \mathrm{kg} / \mathrm{min}$ propofol.

Seventy-one patients were randomly allocated into four groups. All groups received $250 \mathrm{ml}$ of $0.1 \%$ ropivacaine through a PCEA pump (Ambix anaplus ${ }^{\circledR}$, E-Wha Fresenius Kabi, Korea) and each group received either fentayl (group F: fentanyl $4 \mu \mathrm{g}$ / $\mathrm{ml}$ ) or sufentanil (group S1: sufentanil $0.5 \mu \mathrm{g} / \mathrm{ml}$, group S2: sufentanil $0.75 \mu \mathrm{g} / \mathrm{ml}$, and group S3: sufentanil $1.0 \mu \mathrm{g} / \mathrm{ml}$ ). Epidural analgesia began $30 \mathrm{~min}$ before the end of surgery. The PCEA pump was programmed to deliver a $2 \mathrm{ml}$ bolus with a lockout interval of $12 \mathrm{~min}$ and background infusion of $4 \mathrm{ml} / \mathrm{h}$.

An anesthesiologist that was unaware of the group assignment evaluated the postoperative pain score, incidence of side effects (such as hypotension, nausea/vomiting, pruritus, headache, sedation, respiratory depression and numbness) and degree of satisfaction for PCEA on 1, 6, 12, 24, 48 hours following surgery. The pain score was evaluated using VAS (visual analogue scale, $0-10$ ).

Hypotension was defined when systolic arterial blood pressure decreased to less than $90 \mathrm{mmHg}$ or mean arterial pressure decreased to a level of $20 \%$ above baseline following which the patient received ephedrine $8 \mathrm{mg}$ intravenously. When the patient complained of nausea or vomiting, IV ondansetron 4 mg IV was administrated and for respiratory depression, IV naloxone $200 \mu \mathrm{g} I V$ was administrated.

The overall satisfaction score according to PCEA was recorded using a 4-point categorical scale (very good, good, fair, and poor) 48 hours after surgery. The duration of the operation, duration of anesthesia and level of blood loss was recorded.

Data was collected and analyzed using SPSS v 14.0k (SPSS 
Table 1. Patient Demographics and Anesthetic Observations

\begin{tabular}{lcccc}
\hline Variables & $\begin{array}{c}\text { Group F } \\
(\mathrm{n}=20)\end{array}$ & $\begin{array}{c}\text { Group S1 } \\
(\mathrm{n}=17)\end{array}$ & $\begin{array}{c}\text { Group S2 } \\
(\mathrm{n}=17)\end{array}$ & $\begin{array}{c}\text { Group S3 } \\
(\mathrm{n}=17)\end{array}$ \\
\hline Age (yr) & $69.1 \pm 7.2$ & $69.7 \pm 6.4$ & $68.4 \pm 5.9$ & $66.9 \pm 7.9$ \\
Gender (M/F) & $6 / 14$ & $4 / 13$ & $3 / 14$ & $4 / 13$ \\
Weight (kg) & $62.3 \pm 10.9$ & $57.6 \pm 8.1$ & $56.9 \pm 7.8$ & $60.2 \pm 8.2$ \\
Height (cm) & $154.5 \pm 9.7$ & $155.1 \pm 8.2$ & $155.1 \pm 8.3$ & $154.9 \pm 10.0$ \\
$\mathrm{~T}_{\text {op }}$ (min) & $113.3 \pm 24.3$ & $100.0 \pm 31.8$ & $91.8 \pm 17.3$ & $117.4 \pm 39.5$ \\
$\mathrm{~T}_{\text {anes }}(\mathrm{min})$ & $191.0 \pm 20.4$ & $175.3 \pm 35.4$ & $177.1 \pm 26.6$ & $205.0 \pm 46.7$ \\
ASA I & 6 & 6 & 5 & 3 \\
ASA II & 12 & 11 & 1 & 13 \\
ASA III & 2 & 0 & $473 \pm 75$ & 1 \\
Blood loss (ml) & $490 \pm 155$ & $582 \pm 390$ & $523 \pm 139$ \\
\hline
\end{tabular}

Values are mean \pm SD or number of patients, Group F: $0.1 \%$ ropivacaine + fentanyl $4 \mu \mathrm{g} / \mathrm{ml}$, Group S1: $0.1 \%$ ropivacaine + sufentanil $0.5 \mu \mathrm{g} /$ $\mathrm{ml}$, Group S2: $0.1 \%$ ropivacaine + sufentanil $0.75 \mu \mathrm{g} / \mathrm{ml}$, Group S3: $0.1 \%$ ropivacaine + sufentanil $1.0 \mu \mathrm{g} / \mathrm{ml}, \mathrm{T}_{\mathrm{op}}$ : duration of operation, $\mathrm{T}_{\text {anes }}$ : duration of anesthesia, ASA: physical status classification of patients according to the American society of anesthesiologists, All drugs were epidurally administered.

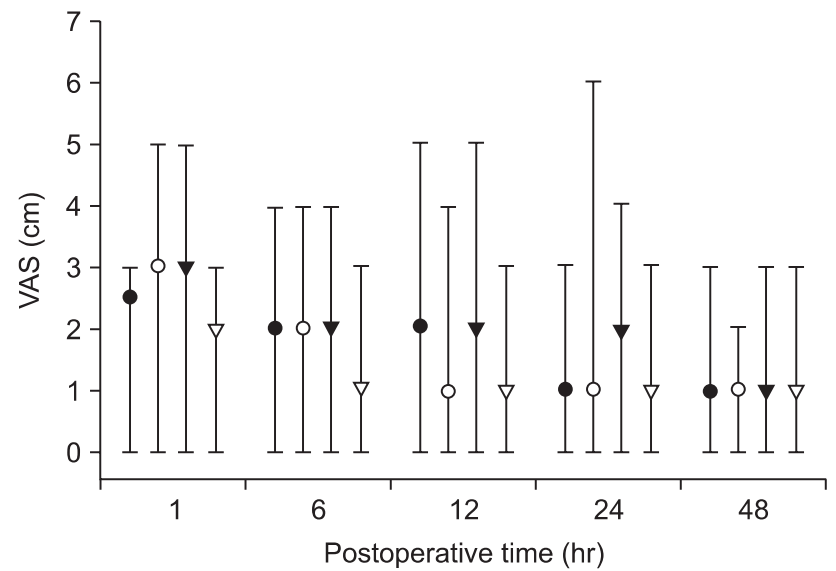

Fig. 1. Changes in postoperative pain in visual analogue scale (VAS, $\mathrm{cm})$. Values are median and range. All drugs were epidurally administered. ๑: group F (0.1\% ropivacaine $250 \mathrm{ml}+$ fentanyl $4 \mu \mathrm{g} / \mathrm{ml}), \bigcirc$ : group S1 (0.1\% ropivacaine $250 \mathrm{ml}+$ sufentanil $0.5 \mu \mathrm{g} / \mathrm{ml}), \nabla$ : group S2 $(0.1 \%$ ropivacaine $250 \mathrm{ml}+$ sufentanil $0.75 \mu \mathrm{g} / \mathrm{ml}), \nabla$ : group S3 ( $0.1 \%$ ropivacaine $250 \mathrm{ml}+$ sufentanil $1.0 \mu \mathrm{g} / \mathrm{ml})$.

inc., Chicago, USA). All variables are presented as means \pm the standard deviation (SD). Continuous variables were analyzed using one way ANOVA after the Komogorov-Smirnov or Kruskal-Wallis test. The difference of the pain score among groups was calculated using the Kruskal-Wallis test. Categorical values were analyzed with the chi-square test or Fisher's exact test. A P value $<0.05$ was considered significant.

\section{Results}

All groups of patients were similar with respect to demographic and anesthetic data (Table 1). Postoperative pain score (VAS) decreased gradually according to time. However, pain control was successful in every group. Also, there was no significant difference of VAS in each group (Fig. 1). Nausea
Table 2. The Incidence of Recorded Side Effects

\begin{tabular}{lllll}
\hline \multicolumn{1}{c}{ Variables } & $\begin{array}{c}\text { Group F } \\
(\mathrm{n}=20)\end{array}$ & $\begin{array}{c}\text { Group S1 } \\
(\mathrm{n}=17)\end{array}$ & $\begin{array}{l}\text { Group S2 } \\
(\mathrm{n}=17)\end{array}$ & $\begin{array}{l}\text { Group S3 } \\
(\mathrm{n}=17)\end{array}$ \\
\hline Nausea/Vomiting & $7(35 \%)$ & $4(23.5 \%)$ & $5(29.4 \%)$ & $7(41.2 \%)$ \\
Pruritus & $3(15 \%)$ & $0(0 \%)$ & $5(29.4 \%)^{*}$ & $7(41.2 \%)^{*}$ \\
Headache & $5(25 \%)$ & $2(11.8 \%)$ & $4(23.5 \%)$ & $2(11.8 \%)$ \\
Numbness & $4(20 \%)$ & $5(29.4 \%)$ & $2(11.8 \%)$ & $3(17.6 \%)$ \\
Sedation & $0(0 \%)$ & $3(17.6 \%)$ & $0(0 \%)$ & $3(17.6 \%)$ \\
Hypotension & $0(0 \%)$ & $1(5.9 \%)$ & $0(0 \%)$ & $0(0 \%)$ \\
Respiratory depression & $0(0 \%)$ & $0(0 \%)$ & $0(0 \%)$ & $0(0 \%)$ \\
\hline
\end{tabular}

Values are number of patients (\%). Group F: $0.1 \%$ ropivacaine + fentanyl $4 \mu \mathrm{g} / \mathrm{ml}$, Group S1: $0.1 \%$ ropivacaine + sufentanil $0.5 \mu \mathrm{g} /$ $\mathrm{ml}$, Group S2: 0.1\% ropivacaine + sufentanil $0.75 \mu \mathrm{g} / \mathrm{ml}$, Group S3: $0.1 \%$ ropivacaine + sufentanil $1.0 \mu \mathrm{g} / \mathrm{ml}$. All drugs were epidurally administered. $* \mathrm{P}<0.05$ compared with group $\mathrm{S} 1$.

Table 3. Patient Assessment of the Effectiveness of Pain Control

\begin{tabular}{lcccc}
\hline \multicolumn{1}{c}{ Variables } & $\begin{array}{c}\text { Group F } \\
(\mathrm{n}=20)\end{array}$ & $\begin{array}{c}\text { Group S1 } \\
(\mathrm{n}=17)\end{array}$ & $\begin{array}{c}\text { Group S2 } \\
(\mathrm{n}=17)\end{array}$ & $\begin{array}{c}\text { Group S3 } \\
(\mathrm{n}=17)\end{array}$ \\
\hline Very good & $5(25 \%)$ & $1(5.9 \%)$ & $6(35.3 \%)$ & $1(5.9 \%)$ \\
Good & $10(50 \%)$ & $13(76.5 \%)$ & $10(58.8 \%)$ & $13(76 . \%)$ \\
Fair & $5(25 \%)$ & $3(17.6 \%)$ & $1(5.9 \%)$ & $3(17.6 \%)$ \\
Poor & $0(0 \%)$ & $0(0 \%)$ & $0(0 \%)$ & $0(0 \%)$ \\
\hline
\end{tabular}

Values are numbers of patients (\%). Group F: $0.1 \%$ ropivacaine + fentanyl $4 \mu \mathrm{g} / \mathrm{ml}$, Group S1: $0.1 \%$ ropivacaine + sufentanil $0.5 \mu \mathrm{g}$ / $\mathrm{ml}$, Group S2: $0.1 \%$ ropivacaine + sufentanil $0.75 \mu \mathrm{g} / \mathrm{ml}$, Group S3: $0.1 \%$ ropivacaine + sufentanil $1.0 \mu \mathrm{g} / \mathrm{ml}$. All drugs were epidurally administered.

and vomiting were the most common side effects $(\mathrm{n}=23)$ and pruritus $(n=15)$, numbness $(n=14)$, headache $(n=13)$ and sedation $(n=6)$ also occurred, but no respiratory depression was observed. The incidence of pruritus was significantly lower in group S1 than in group S2 $(\mathrm{P}=0.041)$, and lower in group S1 than in group $\mathrm{S} 3(\mathrm{P}=0.003)$ (Table 2$)$. There were no differences in the degree of satisfaction for PCEA (Table 3). 


\section{Discussion}

After Hip or knee joint replacement arthroplasty, PCEA for relieving postoperative pain with ropivacaine, sufentanil and fentanyl were able to achieve satisfactory pain relief effects (VAS $\leq 3$ ). There were also no differences in the incidence of side effects and the degree of satisfaction.

In general, patients undergoing hip or knee replacement arthroplasty experienced severe pain after surgery. In addition, most patients were aged above 60 years $(91.5 \%)$ in this study. In elderly patients, postoperative pain can cause or increase respiratory and cardiovascular complications. Therefore, careful pain management is critical.

PCEA reduces pathophysiological changes associated with surgery, induces faster recovery of gastrointestinal function, reduces myocardial ischemia and reduces respiratory complications in elderly patients. Each of these reasons improves the prognosis [10-12]. In addition, pain relief of PCEA is more effective than intravenous PCA and the requirement of opioids is reduced which results in a higher degree of satisfaction [1].

Among the local anesthetics in PCEA, ropivacaine has a similar onset time, duration and intensity of sensory nerve blocking as compared with bupivacaine. Otherwise, ropivacaine has lower central nervous system toxicity and cardiac toxicity and has shorter duration as well as lower intensity of motor blocking than bupivacaine $[13,14]$. The two drug's activity ratio is reported as $0.6[15,16]$. According to the given activity ratio ( $0.15 \%$ ropivacaine and $0.75 \%$ bupivacaine), sensory block is similar but in ropivacaine, the intensity is lower and the duration is shorter than in bupivacaine [17].

Epidural infusion of local anesthetics alone results in higher drug dosage. Following that, early ambulation is difficult because the motor nerves are blocked and hemodynamic instability occurs due to sympathetic nerves being blocked $[18,19]$. Therefore, lowering the concentration of local anesthetics induces hemodynamic stability. This also prevents gait disorders caused by proprioceptor block and motor nerve block and prevents the pressure injury due to sensory nerve block [20]. However, the analgesic effect is also reduced [21,22]. Therefore, lowering the concentration of local anesthetics and combination of epidural opioids can reduce the side effects of local anesthetics and the analgesic effect can be magnified.

Lorenzini et al. [23] reported patients receiving knee surgery with epidural injection of $0.2 \%$ ropivacaine with added sufentanil $1.0 \mu \mathrm{g} / \mathrm{ml}$ to have a more effective analgesic effect than only $0.2 \%$ ropivacaine. Kampe et al. [24] reported patients receiving hip replacement arthroplasty with epidural injection of $0.1 \%$ ropivacaine with added sufentanil $1.0 \mu \mathrm{g} / \mathrm{ml}$ to have a reduction of postoperative use of analgesics without increasing the incidence of side effects by using only $0.1 \%$ ropivacaine.

Opioid-based techniques have been used widely. Clinically, epidurally administered lipophilic fentanyl and sufentanil are often used because these have a rapid onset of analgesic effects and are a good choice for pain relief. Hydrophilic morphine is also used in some cases [18,25]. Since fentanyl and sufentanil have higher affinity on dorsal horn opioid receptors than lipid insoluble morphine, they have faster and more potent analgesic effects. Also, the degree of rostral migration of the lipophilic fentanyl and sufentanil in the CSF is less than morphine. For these reasons, they have a low incidence of prolonged respiratory depression. But, a continuous infusion was required for postoperative analgesia because the duration of action was shorter [1,20].

The lipid solubility of sufentanil was 1,000 folds higher than morphine and 8-10 folds higher than fentanyl. Sufentanil was more selective against the $\mu$ receptor antagonist than fentanyl and had a higher intensity than fentanyl or morphine. Also, the effect on the motor nerve was low, and $0.5-1.0 \mu \mathrm{g} / \mathrm{ml}$ sufentanil was co-administered with local anesthetics [1].

In previous studies, the optimal concentration of ropivacaine when used for epidural analgesia is $0.1-0.2 \%[26,27]$ and fentanyl $4 \mu \mathrm{g} / \mathrm{ml}$ is often used for pain control [1,27]. We therefore used $0.1 \%$ ropivacaine and fentanyl $4 \mu \mathrm{g} / \mathrm{ml}$ in the control group. The treatment is considered effective when it decreases the VAS score below $30 \mathrm{~mm}$ clinically [28]. In this study, the treatment demonstrated adequate effects in all four groups.

Postoperative nausea/vomiting (PONV) occurred due to many reasons and $20-30 \%$ patients experienced PONV after general anesthesia [29]. In addition, epidural infusion of local anesthetics can cause hypotension, and consequently cause nausea/vomiting. But in this study, only one patient experienced hypotension and this patient had no PONV. So, it was concluded that hypotension had no effect on nausea/vomiting. Intravenous or epidural opioid injections can increase the incidence of PONV. Statistical analyses revealed no meaningful differences between sufentanil groups but the incidences of PONV increased when the dose of sufentanil was raised. So, there is a possibility that sufentanil and general anesthesia might be risk factors of nausea and vomiting. However, to understand the exact effects further study is needed. Usually PONV subsided spontaneously or by intravenous ondansetron $4 \mathrm{mg}$. The incidences of pruritus were only significantly increased when the dose of sufentanil was raised but most symptoms were mild and subsided when PCEA stopped. Sedation occurred 1 hour after surgery in 6 patients but this symptom disappeared spontaneously. Sedation showed in 6 patients within 1 hour after operation, which regressed without specific care. Sedation showed no significant difference within groups. 
Numbness was associated with the concentrations of ropivacaine and the level of lumbar block. Choi et al. [30] reported that when patients received $0.15 \%$ ropivacaine with fentanyl $2 \mu \mathrm{g} / \mathrm{ml}$ for postoperative epidural analgesia at a rate of $5 \mathrm{ml} / \mathrm{hr}$, there was no experience of numbness. Ahn et al. [27] reported that when patients received $0.2 \%$ ropivacaine with fentanyl $4 \mu \mathrm{g} / \mathrm{ml}$ at a rate of $2 \mathrm{ml} / \mathrm{hr}, 1$ of 32 patients (3.2\%) experienced varying degrees of numbness. In this study, the incidence of numbness is higher than in other studies. It is possible that numbness was confused with surgical pain or paresthesia and therefore not measured precisely. Thirteen cases of headache occurred but no dural punctures were observed. It was therefore concluded that headaches occurred due to inhalation anesthetics [31] and no patients complained of headache after or at the time of being discharged. The patients answered positively about satisfaction (very good, good) and there were $75 \%$ in group F, $82.4 \%$ in group S1, $94.1 \%$ in group S2 and $82.4 \%$ in group S3. No statistical differences were observed between these measurements.

A limitation of this study was the small sample size of each group. We therefore can not effectively detect the differences in the incidence of side effects. We calculated a sample size with the degree of pain scores in each group yet the sample size was not enough for the detection of rare side effects.

In this study, sufentanil and fentanyl for postoperative epidural analgesia seem to have the same analgesic effects and there are no differences in the incidence of side effects and the degree of satisfaction in each group, so sufentanil should replace fentanyl. Since there are no differences in the incidence of side effects and the postoperative pain score in each sufentanil group, we conclude that the smallest dose of sufentanil $0.5 \mu \mathrm{g} / \mathrm{ml}$ is enough for PCEA and believe that more studies on the smaller dose of sufentanil are needed for minimizing the incidence of side effects.

In conclusion, after hip or knee joint replacement, PCEA for relieving postoperative pain with ropivacaine, sufentanil and fentanyl were able to achieve a satisfactory pain relief effect (VAS $\leq 3$ ). Using different doses of the sufentanil group, similar analgesic effects were observed. Therefore, sufentanil like fentanyl for PCEA can be used effectively and sufentanil $0.5 \mu \mathrm{g} / \mathrm{ml}$ is enough for postoperative pain control and side effects. Consequently, we think sufentanil $0.5 \mu \mathrm{g} / \mathrm{ml}$ is the recommended dose for PCEA.

\section{References}

1. Wu CL. Acute postoperative pain. In: Miller's Anesthesia. 6th ed. Edited by Miller RD: Philadelphia, Churchill Livingstone. 2005, pp 2729-62.

2. Polley LS, Columb MO, Wagner DS, Naughton NN. Dose-depen- dent reduction of the minimum local analgesic concentration of bupivacaine by sufentanil for epidural analgesia in labor. Anesthesiology 1998; 89: 626-32.

3. Kim DH. Postoperative pain management. In: Pain Medicine. 2nd ed. Edited by the Korean Pain Society: Seoul, Koonja Publishing Inc. 2000, pp 283-304.

4. de Leon-Casasola OA, Lema MJ. Epidural bupivacaine/sufentanil therapy for postoperative pain control in patients tolerant to opioid and unresponsive to epidural bupivacaine/morphine. Anesthesiology 1994; 80: 303-9.

5. Kim WJ, Choi JB, Lee SJ, Yoon DM, Lee YW. Comparison of sufentanil and morphine with ropivacaine for patient-controlled epidural analgesia after gastrectomy. Korean J Anesthesiol 2005; 49: 216-21.

6. Kaya T, Büyükkoçak U, Başar H, Sağsöz N. Comparison of epidural ropivacaine $0.2 \%$ and ropivacaine $0.2 \%$ in combination with sufentanil 0.75 microg mL-1 for postcaesarean analgesia. Agri 2008; 20: 30-7.

7. Todd KH, Funk JP. The minimum clinically important difference in physician-assigned visual analog pain scores. Acad Emerg Med 1996; 3: 142-6.

8. Todd KH. Clinical versus statistical significance in the assessment of pain relief. Ann Emerg Med 1996; 27: 439-41.

9. Farrar JT, Portenoy RK, Berlin JA, Kinman JL, Strom BL. Defining the clinically important difference in pain outcome measures. Pain 2000; 88: 287-94.

10. Rigg JR, Jamrozik K, Myles PS, Silbert BS, Peyton PJ, Parsons RW, et al. Epidural anaesthesia and analgesia and outcome of major surgery: a randomised trial. Lancet 2002; 359: 1276-82.

11. Mann C, Pouzeratte Y, Boccara G, Peccoux C, Vergne C, Brunat G, et al. Comparison of intravenous or epidural patient-controlled analgesia in the elderly after major abdominal surgery. Anesthesiology 2000; 92: 433-41.

12. Scheinin B, Asantila R, Orko R. The effect of bupivacaine and morphine on pain and bowel function after colonic surgery. Acta Anaesthesiol Scand 1987; 31: 161-4.

13. Bader AM, Datta S, Flanagan H, Covino BG. Comparison of bupivacaine- and ropivacaine-induced conduction blockade in the isolated rabbit vagus nerve. Anesth Analg 1989; 68: 724-7.

14. Reiz S, Häggmark S, Johansson G, Nath S. Cardiotoxicity of ropivacaine--a new amide local anaesthetic agent. Acta Anaesthesiol Scand 1989; 33: 93-8.

15. Polley LS, Columb MO, Naughton NN, Wagner DS, van de Ven CJ. Relative analgesic potencies of ropivacaine and bupivacaine for epidural analgesia in labor: implications for therapeutic indexes. Anesthesiology 1999; 90: 944-50.

16. Capogna G, Celleno D, Fusco P, Lyons G, Columb M. Relative potencies of bupivacaine and ropivacaine for analgesia in labour. Br J Anaesth 1999; 82: 371-3.

17. Kerkkamp HE, Gielen MJ, Edström HH. Comparison of 0.75\% ropivacaine with epinephrine and $0.75 \%$ bupivacaine with epinephrine in lumbar epidural anesthesia. Reg Anesth 1990; 15: 204-7.

18. Wheatley RG, Schug SA, Watson D. Safety and efficacy of postoperative epidural analgesia. Br J Anaesth 2001; 87: 47-61.

19. Etches RC, Writer WD, Ansley D, Nydahl PA, Ong BY, Lui A, et al. Continuous epidural ropivacaine $0.2 \%$ for analgesia after lower 
abdominal surgery. Anesth Analg 1997; 84: 784-90.

20. Kim DH. Acute pain management. In: Anesthesia. Edited by the Korean Society of Anesthesiologists: Seoul, Koonja Publishing Inc. 2002, pp 1463-85.

21. Murdoch JA, Dickson UK, Wilson PA, Berman JS, Gad-Elrab RR, Scott NB. The efficacy and safety of three concentrations of levobupivacaine administered as a continuous epidural infusion in patients undergoing orthopedic surgery. Anesth Analg 2002; 94: 438-44.

22. Scott DA, Chamley DM, Mooney PH, Deam RK, Mark AH, Hägglöf B. Epidural ropivacaine infusion for postoperative analgesia after major lower abdominal surgery--a dose finding study. Anesth Analg 1995; 81: 982-6.

23. Lorenzini C, Moreira LB, Ferreira MB. Efficacy of ropivacaine compared with ropivacaine plus sufentanil for postoperative analgesia after major knee surgery. Anaesthesia 2002; 57: 424-8.

24. Kampe S, Weigand C, Kaufmann J, Klimek M, König DP, Lynch J. Postoperative analgesia with no motor block by continuous epidural infusion of ropivacaine $0.1 \%$ and sufentanil after total hip replacement. Anesth Analg 1999; 89: 395-8.

25. de Leon-Casasola OA, Lema MJ. Postoperative epidural opioid analgesia: what are the choices? Anesth Analg 1996; 83: 867-75.
26. Scott DA, Blake D, Buckland M, Etches R, Halliwell R, Marsland C, et al. A comparison of epidural ropivacaine infusion alone and in combination with 1,2 , and 4 microg/mL fentanyl for seventy-two hours of postoperative analgesia after major abdominal surgery. Anesth Analg 1999; 88: 857-64.

27. Ahn EK, Kim JH, Chon SS, Lee GM, Kim MO, Kang SH, et al. The comparison of ropivacaine and bupivacaine in epidural patient controlled analgesia (PCA). Korean J Anesthesiol 2002; 42: 646-51.

28. Yang CW, Park JM, Lim YS, Cho CK, Kim KS, Kim EK, et al. Postoperative epidural analgesia using $0.1 \%$ levobupivacaine or $0.1 \%$ ropivacaine combined with sufentanil in gynecologic surgery. Korean J Anesthesiol 2007; 53: 746-52.

29. Apfel CC, Korttila K, Abdalla M, Kerger H, Turan A, Vedder I, et al. A factorial trial of six interventions for the prevention of postoperative nausea and vomiting. N Engl J Med 2004; 350: 2441-51.

30. Choi JY, Kim YJ, Baik HJ, Kim JH. Comparison of 0.15\% ropivacaine/ fentanyl and $0.1 \%$ levobupivacaine/fentanyl infused for postoperative epidural analgesia. Korean J Anesthesiol 2006; 50: 77-83.

31. Fennelly M, Galletly DC, Purdie GI. Is caffeine withdrawal the mechanism of postoperative headache? Anesth Analg 1991; 72: 449-53. 